\title{
Neutrophil-to-lymphocyte Ratio Associated With an Increased Risk of Mortality in Patients With Critical Limb Ischemia
}

\author{
Min-I Su \\ Taitung MacKay Memorial Hospital \\ Cheng-Wei Liu ( $\sim$ issac700319@gmai.com ) \\ Tri-Service General Hospital Songshan Branch
}

\section{Research Article}

Keywords: lower extremity artery disease, critical limb ischemia, neutrophil-to-lymphocyte ratio, major adverse cardiac events, major adverse limb events

Posted Date: February 24th, 2021

DOI: https://doi.org/10.21203/rs.3.rs-243462/v1

License: (c) (i) This work is licensed under a Creative Commons Attribution 4.0 International License. Read Full License 


\section{Abstract}

Purpose: Association of the neutrophil-to-lymphocyte ratio (NLR) with mortality has not been comprehensively explored in critical limb ischemia (CLI) patients. We investigated the association between the NLR and clinical outcomes in CLI.

Materials and methods: We retrospectively enrolled consecutive CLI patients during 1/1/2013-12/31/2018. Receiver operating characteristic curve analysis determined NLR cutoffs for 1-year in-hospital, all-cause and cardiac-related mortality, and major adverse cardiovascular events (MACEs) and limb events (MALEs).

Results: Among 195 patients (age, 74.0 years, SD: 11.5; 51.8\% male; BMI, 23.4 kg/m², SD: 4.2), 14.4\% exhibited acute limb ischemia. After 1 year, patients with an NLR>8 had higher in-hospital mortality (21.1\% vs. $3.6 \%, P<0.001)$, all-cause mortality (54.4\% vs. $13.8 \%, P<0.001)$, cardiac-related mortality (28.1\% vs. $6.5 \%, P<0.001)$, MACE $(29.8 \%$ vs. $13.0 \%, P=0.008)$, and MALE ( $28.1 \%$ vs. $13.0 \%, P=0.021)$ rates than those with an NLR<8. In multivariate logistic regression, an NLR $\geq 8$ was significantly associated with all-cause ( $\mathrm{P}<0.001)$ and cardiac-related (adjusted HR: 5.286, 95\% Cl: 2.075-13.47, $\mathrm{P}<0.001)$ mortality, and an NLR $\geq 6$ was significantly associated with MALEs (adjusted HR: $2.804,95 \% \mathrm{Cl}: 1.292-6.088, \mathrm{P}=0.009$ ).

Conclusion: CLI patients with high NLRs had higher risks of 1-year all-cause and cardiac-related mortality and MALEs. The NLR can be used for prognostic prediction in these patients.

\section{Introduction}

The neutrophil-to-lymphocyte ratio (NLR) is widely used as a prognostic biomarker in various diseases, such as cancer and cardiovascular disease ${ }^{1,2}$. Both of these disorders have a common pathophysiology involving inflammatory processes that can be roughly represented as the ratio of neutrophils ${ }^{3,4}$; the proportion of lymphocytes indicates the host immune response and has been associated with mortality in healthy individuals ${ }^{5}$. The NLR combines the properties of the inflammatory and immune responses and thereby enables the prediction of outcomes in patients with diverse atherosclerotic cardiovascular and peripheral vascular diseases ${ }^{6,7}$.

An elevated NLR has been associated with unfavorable neurological outcomes and increased mortality in patients with ischemic stroke $^{8}$, with an increased risk of mortality and major adverse cardiovascular events (MACE) in patients with acute myocardial infarction $^{9}$, and with the severity of low extremity artery disease (LEAD) in cohort studies ${ }^{10,11}$. Other cohort studies have further reported the association between NLR and mortality in patients with critical limb ischemia (CLI) ${ }^{12,13}$. However, no studies have reported the comprehensive outcomes of all-cause and cardiac-related mortality, MACE, and major adverse limb events (MALE) in patients with CLI. Therefore, we conducted the present study to investigate the association between the NLR and outcomes in patients with CLI.

\section{Results}

The study consisted of 195 patients with CLI who underwent percutaneous transluminal angioplasty after we excluded three patients with a nonsalvageable limb who refused amputation surgery and two patients with missing data for NLR. The patients had a mean age of 74 years, (SD:12) and a mean NLR of 8.2 (SD:10.0), with $52.3 \%$ male and Rutherford stages IV, V, and VI accounting for $27.4 \%, 66.0 \%$, and $6.6 \%$ of the patients, respectively. We used receiver operating characteristic curves to identify cut-off values for NLR; these cut-off values were eight for one-year all-cause and cardiac-related mortality and MACE, six for MALE, and five for in-hospital mortality. Figure 1 shows the area under the curve for the study outcomes. The incidences of the primary outcomes were $25.4 \%$ for all-cause mortality, $12.7 \%$ for cardiac-related mortality, $17.8 \%$ for MACE, and $17.3 \%$ for MALE, and the incidence of the secondary outcome was $8.6 \%$ for in-hospital all-cause mortality. Regarding the Rutherford classification, in CLI patients with Rutherford stages IV, V, and VI, the incidences of all-cause mortality were $18.9 \%, 26.4 \%$, and $46.2 \%$, respectively, and those of MALE were $0 \%, 22.5 \%$ and $38.5 \%$, respectively.

With regard for the primary study outcomes, there was no significant difference in baseline characteristics, such as the ratio of smoking and chronic kidney disease, a history of amputation, and heart failure status, between patients with NLR $\geq 8$ vs. NLR $<8$; 
however, compared with patients with NLR $<8$, those with NLR $\geq 8$ had higher heart rates ( 93.3 vs. 86.5 beats per minute, $P=$ $0.014)$, a higher rate of presenting with acute limb ischemia $(29.8 \%$ vs. $9.2 \%, P=0.001)$ and a more severe Rutherford stage ( $70.2 \%$ vs. $65.2 \%$ for stage $V, 14.0 \%$ vs $3.5 \%$ for stage $\mathrm{Vl}, \mathrm{P}=0.005)$. Medication use at baseline did not differ between the two groups except that there was a lower rate of cilostazol use in the patients with NLR $>8$ than in those with NLR $<8(31.6 \%$ vs. $51.8 \%, \mathrm{P}=0.012$ ). We show the patients' baseline characteristics, laboratory data, and medication use by NLR $\geq 8$ vs. $<8$ in relation to one-year all-cause and cardiac-related mortality and MACE in Table 1 ; by NLR $\geq 5$ vs. NLR $<5$ in relation to in-hospital mortality in Supplementary Table S1; and by NLR $\geq 6$ vs. $<6$ in relation to MALE in Supplementary Table S2. In our study, the

mean NLR value was 6.1 (SD:7.4) for Rutherford stage IV, 8.6 (SD:1.07) for Rutherford stage V, and 13.2 (SD: 10.6) for Rutherford stage Vl. 
Table 1

Baseline and procedural characteristics and laboratory data in patients with critical limb ischemia

\begin{tabular}{|c|c|c|c|c|c|}
\hline & NLR $<\varepsilon$ & & $N L R \geq 8$ & & $\mathbf{P}$ \\
\hline & $N=138$ & & $N=57$ & & \\
\hline Age (years) & 73.6 & $(11.8)$ & 75.1 & $(10.9)$ & 0.393 \\
\hline Male gender & 70 & $50.7 \%$ & 31 & $54.4 \%$ & 0.753 \\
\hline Body mass index $\left(\mathrm{kg} / \mathrm{m}^{2}\right)$ & 23.6 & $(4.0)$ & 23.0 & $(4.5)$ & 0.358 \\
\hline Heart rate at baseline (beats per minute) & 86.1 & $(15.6)$ & 93.3 & $(21.7)$ & 0.025 \\
\hline Systolic BP at baseline $(\mathrm{mm} \mathrm{Hg})$ & 148.6 & $(31.0)$ & 144.0 & $(33.1)$ & 0.407 \\
\hline Diastolic BP at baseline $(\mathrm{mm} \mathrm{Hg})$ & 74.7 & $(13.0)$ & 76.3 & $(17.7)$ & 0.531 \\
\hline Current/past smoker & 35 & $25.4 \%$ & 11 & $19.3 \%$ & 0.459 \\
\hline Alcohol intake & 38 & $27.5 \%$ & 17 & $29.8 \%$ & 0.730 \\
\hline Family history of premature CAD & 2 & $1.4 \%$ & 0 & $0 \%$ & 1.000 \\
\hline History of hypertension & 97 & $70.3 \%$ & 32 & $56.1 \%$ & 0.068 \\
\hline History of diabetes mellitus & 97 & $70.3 \%$ & 37 & $64.9 \%$ & 0.499 \\
\hline History of insulin use & 20 & $14.5 \%$ & 5 & $8.8 \%$ & 0.350 \\
\hline History of dyslipidemia & 22 & $15.9 \%$ & 11 & $19.3 \%$ & 0.675 \\
\hline Normal kidney function & 89 & $64.5 \%$ & 34 & $59.6 \%$ & 0.150 \\
\hline Chronic kidney disease & 26 & $18.4 \%$ & 7 & $12.3 \%$ & \\
\hline End-stage renal disease & 23 & $16.7 \%$ & 16 & $28.1 \%$ & \\
\hline History of CAD & 52 & $37.7 \%$ & 23 & $40.4 \%$ & 0.748 \\
\hline History of myocardial infarction & 11 & $8.0 \%$ & 2 & $3.5 \%$ & 0.355 \\
\hline History of atrial fibrillation & 21 & $15.2 \%$ & 5 & $8.8 \%$ & 0.258 \\
\hline History of chronic heart failure & 29 & $21.0 \%$ & 13 & $22.8 \%$ & 0.920 \\
\hline NYHA class I & 6 & $4.3 \%$ & 4 & $7.0 \%$ & \\
\hline NYHA class II & 8 & $5.8 \%$ & 4 & $7.0 \%$ & \\
\hline NYHA class III & 11 & $8.0 \%$ & 4 & $7.0 \%$ & \\
\hline NYHA class IV & 4 & $2.9 \%$ & 1 & $1.8 \%$ & \\
\hline History of carotid artery stenosis & 3 & $2.2 \%$ & 0 & $0 \%$ & 0.557 \\
\hline History of ischemic stroke & 24 & $17.4 \%$ & 10 & $17.5 \%$ & 1.000 \\
\hline Ongoing cancer & 10 & $7.1 \%$ & 2 & $3.5 \%$ & 0.514 \\
\hline History of amputation & & & & & 0.991 \\
\hline Above-knee amputation & 4 & $2.9 \%$ & 2 & $3.5 \%$ & \\
\hline
\end{tabular}

Values are expressed as numbers (standard deviation) or numbers and percentages.

$\mathrm{CAD}$ = coronary artery disease; NYHA = New York Heart Association; $\mathrm{BP}=$ blood pressure; NLR = neutrophil-to-lymphocyte ratio; $\mathrm{ACEI}$ = angiotensin-converting enzyme inhibitor; $\mathrm{ARB}$ = angiotensin receptor blocker 


\begin{tabular}{|c|c|c|c|c|c|}
\hline \multirow[b]{2}{*}{ Below-knee amputation } & \multicolumn{2}{|c|}{$N L R<8$} & \multicolumn{2}{|c|}{$N L R \geq 8$} & \multirow[t]{2}{*}{$\mathbf{P}$} \\
\hline & 2 & $1.4 \%$ & 1 & $1.8 \%$ & \\
\hline Forefoot amputation & 3 & $2.2 \%$ & 1 & $1.8 \%$ & \\
\hline Presented with acute ischemic limb & 11 & $8.0 \%$ & 17 & $29.8 \%$ & $<0.001$ \\
\hline Rutherford classification & & & & & 0.005 \\
\hline Class IV & 44 & $31.9 \%$ & 9 & $15.8 \%$ & \\
\hline Class V & 89 & $64.5 \%$ & 40 & $70.2 \%$ & \\
\hline Class VI & 5 & $3.6 \%$ & 8 & $14.0 \%$ & \\
\hline \multicolumn{6}{|l|}{ Laboratory data } \\
\hline Total cholesterol (mg/dl) & 159.2 & $(46.8)$ & 148.0 & $(48.8)$ & 0.160 \\
\hline High-density lipoprotein cholesterol (mg/dl) & 40.9 & $(18.6)$ & 38.2 & $(19.2)$ & 0.639 \\
\hline Low-density lipoprotein cholesterol (mg/dl) & 95.0 & $(34.9)$ & 83.2 & $(43.7)$ & 0.257 \\
\hline Triglyceride (mg/dl) & 151.8 & $(121.7)$ & 117.9 & $(83.2)$ & 0.205 \\
\hline Fasting glucose (mg/dl) & 177.7 & $(95.0)$ & 184.9 & $(126.2)$ & 0.663 \\
\hline Glycosylated hemoglobin (\%) & 7.4 & $(1.8)$ & 7.6 & $(2.1)$ & 0.684 \\
\hline Creatinine $(\mathrm{mg} / \mathrm{dl})$ & 3.3 & $(3.1)$ & 3.8 & $(3.6)$ & 0.288 \\
\hline Alanine transaminase (IU/L) & 18.5 & $(10.4)$ & 33.6 & $(35.2)$ & 0.003 \\
\hline Uric acid (mg/dl) & 5.6 & $(2.2)$ & 6.1 & $(2.9)$ & 0.248 \\
\hline White blood cell count $10^{3} / \mu \mathrm{l}$ & 7.8 & $(3.1)$ & 14.4 & $(5.8)$ & $<0.001$ \\
\hline Neutrophil ratio (\%) & 65.3 & $(12.2)$ & 84.9 & $(5.1)$ & $<0.001$ \\
\hline Lymphocyte ratio (\%) & 20.3 & $(7.8)$ & 5.9 & $(2.5)$ & $<0.001$ \\
\hline NLR & 3.9 & $(1.9)$ & 18.7 & $(13.5)$ & $<0.001$ \\
\hline \multicolumn{6}{|l|}{ Medication use at baseline } \\
\hline Aspirin & 49 & $35.5 \%$ & 18 & $31.6 \%$ & 0.623 \\
\hline Cilostazol & 72 & $52.2 \%$ & 18 & $31.6 \%$ & 0.011 \\
\hline Clopidogrel & 35 & $25.4 \%$ & 18 & $31.6 \%$ & 0.381 \\
\hline Pentoxifylline & 8 & $5.8 \%$ & 0 & $0 \%$ & 0.108 \\
\hline ACEI or ARB & 7 & $5.1 \%$ & 2 & $3.5 \%$ & 1.000 \\
\hline Beta-blocker & 26 & $18.8 \%$ & 9 & $15.8 \%$ & 0.686 \\
\hline Calcium channel blocker & 29 & $21.0 \%$ & 10 & $17.5 \%$ & 0.695 \\
\hline Statin & 28 & $20.3 \%$ & 9 & $15.8 \%$ & 0.550 \\
\hline Urate lowering therapy & 3 & $2.2 \%$ & 2 & $3.5 \%$ & 0.631 \\
\hline \multicolumn{6}{|l|}{ Procedure characteristics } \\
\hline \multicolumn{6}{|c|}{ Values are expressed as numbers (standard deviation) or numbers and percentages. } \\
\hline
\end{tabular}




\begin{tabular}{|c|c|c|c|c|c|}
\hline & \multicolumn{2}{|c|}{$N L R<8$} & \multicolumn{2}{|c|}{$N L R \geq 8$} & $\mathbf{P}$ \\
\hline \multicolumn{6}{|l|}{ Ischemia-related artery } \\
\hline Iliac artery involvement & 16 & $11.6 \%$ & 7 & $12.3 \%$ & 1.000 \\
\hline Superficial femoral artery involvement & 90 & $65.2 \%$ & 33 & $57.9 \%$ & 0.415 \\
\hline Below the knee artery involvement & 25 & $18.1 \%$ & 10 & $17.5 \%$ & 1.000 \\
\hline In-stent restenosis & 2 & $1.4 \%$ & 2 & $3.5 \%$ & 0.582 \\
\hline \multicolumn{6}{|c|}{ Values are expressed as numbers (standard deviation) or numbers and percentages. } \\
\hline
\end{tabular}

The primary outcomes were significantly worse in patients with NLR $\geq 8$ than in those with NLR $<8$ ( $54.4 \%$ vs. $13.8 \%, P<0.001$ for one-year all-cause mortality; $28.1 \%$ vs. $6.5 \%, \mathrm{P}<0.001$ for cardiac-related mortality; $29.8 \%$ vs. $13.0 \%, \mathrm{P}=0.008$ for MACE; and $28.1 \%$ vs. $13.0 \%, P=0.021$ for MALE); the secondary outcomes were also significantly worse in patients with NLR $\geq 8$ than in the patients with NLR $<8(21.1 \%$ vs. $3.6 \%, P<0.001)$. Regarding the primary outcomes in univariate logistic regression analyses, each incremental increase in NLR was associated with increases in all-cause mortality (crude HR: 1.028, 95\% Cl: 1.013-1.042, P< 0.001 ) and cardiac-related mortality (crude HR: $1.025,95 \% \mathrm{Cl}: 1.004-1.047, \mathrm{P}=0.021$ ) but not MACE (crude HR: $1.014,95 \% \mathrm{Cl}$ : $0.990-1.038, \mathrm{P}=0.267$ ) or MALE (crude HR: $1.012,95 \% \mathrm{Cl}: 0.987-1.038, \mathrm{P}=0.346$ ). Incremental increases in NLR were not associated with the secondary outcomes (crude HR: $1.012,95 \% \mathrm{Cl}: 0.965-1.061, \mathrm{P}=0.626$ ). We demonstrate there are associations between NLR and both variables and study outcomes in Table 2. With regard for mortality and MACE, other factors associated with the study outcomes included baseline heart rate and the presence of acute limb ischemia, whereas the Rutherford stage was associated with MALE but not all-cause and cardiac-related mortality and MACE. 
Table 2

Variables associated with study outcomes in patients with critical limb ischemia in logistic regression analyses

\begin{tabular}{|c|c|c|c|c|c|c|c|c|c|c|c|c|}
\hline & $\mathrm{cHR}$ & $95 \% \mathrm{Cl}$ & & $P$ & aHR & $95 \% \mathrm{Cl}$ & & $P$ & aHR & $95 \% \mathrm{Cl}$ & & $\mathbf{P}$ \\
\hline \multicolumn{13}{|l|}{$\begin{array}{l}\text { All-cause } \\
\text { mortality at } \\
\text { one year }\end{array}$} \\
\hline $\begin{array}{l}\text { NLR as a } \\
\text { continuous } \\
\text { variable }^{\mathrm{a}}\end{array}$ & 1.028 & 1.013 & 1.042 & $<.001$ & 1.028 & 1.008 & 1.049 & 0.007 & & & & \\
\hline $\begin{array}{l}\text { NLR } \geq 8 \text { vs. }< \\
8^{a}\end{array}$ & 5.272 & 2.972 & 9.353 & $\begin{array}{l}< \\
0.001\end{array}$ & & & & & 3.599 & 1.818 & 7.123 & $\begin{array}{l}<.001 \\
0.001\end{array}$ \\
\hline Age (years) & 1.031 & 1.004 & 1.059 & 0.023 & 1.013 & 0.983 & 1.044 & 0.400 & 1.014 & 0.983 & 1.045 & 0.393 \\
\hline Male gender & 0.698 & 0.399 & 1.220 & 0.206 & 0.487 & 0.249 & 0.954 & 0.036 & 0.535 & 0.278 & 1.028 & 0.061 \\
\hline $\begin{array}{l}\text { Body mass } \\
\text { index } \\
\left(\mathrm{kg} / \mathrm{m}^{2}\right)\end{array}$ & 0.937 & 0.867 & 1.012 & 0.096 & 0.938 & 0.862 & 1.022 & 0.143 & 0.939 & 0.867 & 1.018 & 0.126 \\
\hline $\begin{array}{l}\text { Smoking (yes } \\
\text { or no) }\end{array}$ & 0.979 & 0.585 & 1.637 & 0.935 & & & & & & & & \\
\hline $\begin{array}{l}\text { Hypertension } \\
\text { (yes or no) }\end{array}$ & 0.618 & 0.353 & 1.080 & 0.091 & & & & & & & & \\
\hline $\begin{array}{l}\text { Heart rate } \\
\text { (beats per } \\
\text { minute) }\end{array}$ & 1.025 & 1.009 & 1.042 & 0.002 & 1.016 & 0.997 & 1.036 & 0.095 & 1.012 & 0.993 & 1.032 & 0.205 \\
\hline $\begin{array}{l}\text { Alanine } \\
\text { transaminase } \\
(\mathrm{IU} / \mathrm{L})\end{array}$ & 1.020 & 1.012 & 1.028 & $\begin{array}{l}< \\
0.001\end{array}$ & 1.011 & 1.001 & 1.022 & 0.045 & 1.010 & 0.999 & 1.021 & 0.063 \\
\hline $\begin{array}{l}\text { Acute } \\
\text { ischemic } \\
\text { limb (yes or } \\
\text { no) }\end{array}$ & 3.607 & 1.965 & 6.620 & $\begin{array}{l}< \\
0.001\end{array}$ & 1.773 & 0.781 & 4.023 & 0.171 & 1.173 & 0.497 & 2.773 & 0.715 \\
\hline $\begin{array}{l}\text { Rutherford } \\
\text { classification } \\
\text { (IV, V or VI) }\end{array}$ & 1.809 & 1.051 & 3.114 & 0.032 & 1.839 & 0.978 & 3.457 & 0.059 & 1.537 & 0.830 & 2.846 & 0.172 \\
\hline \multicolumn{13}{|c|}{ Cardiac-related mortality at one year } \\
\hline $\begin{array}{l}\text { NLR as a } \\
\text { continuous } \\
\text { variable }^{a}\end{array}$ & 1.025 & 1.004 & 1.047 & 0.021 & 1.027 & 0.998 & 1.057 & 0.073 & & & & \\
\hline $\begin{array}{l}\text { NLR } \geq 8 \text { vs. }< \\
8^{a}\end{array}$ & 5.924 & 2.609 & 13.450 & $<.001$ & & & & & 5.286 & 2.075 & 13.47 & $\dot{0.001}$ \\
\hline Age (years) & 1.031 & 0.993 & 1.071 & 0.107 & 1.015 & 0.975 & 1.056 & 0.464 & 1.015 & 0.973 & 1.059 & 0.482 \\
\hline Male gender & 0.693 & 0.315 & 1.527 & 0.363 & 0.539 & 0.222 & 1.308 & 0.172 & 0.577 & 0.243 & 1.370 & 0.212 \\
\hline $\begin{array}{l}\text { Body mass } \\
\text { index } \\
\left(\mathrm{kg} / \mathrm{m}^{2}\right)\end{array}$ & 0.940 & 0.846 & 1.044 & 0.247 & 0.945 & 0.845 & 1.057 & 0.352 & 0.942 & 0.846 & 1.049 & 0.277 \\
\hline $\begin{array}{l}\text { Smoking (yes } \\
\text { or no) }\end{array}$ & 1.113 & 0.561 & 2.207 & 0.759 & & & & & & & & \\
\hline
\end{tabular}

${ }^{\text {a }}$ NLR as a continuous variable and NLR as a binary variable were not simultaneously adjusted in the multivariate logistic regression analyses. $\mathrm{CHR}=$ crude hazard ratio; aHR = adjusted hazard ratio; Cl: confidence interval. 


\begin{tabular}{|c|c|c|c|c|c|c|c|c|c|c|c|c|}
\hline & $\mathrm{cHR}$ & $95 \% \mathrm{Cl}$ & & $P$ & aHR & $95 \% \mathrm{Cl}$ & & $P$ & aHR & $95 \% \mathrm{Cl}$ & & $P$ \\
\hline $\begin{array}{l}\text { Hypertension } \\
\text { (yes or no) }\end{array}$ & 0.612 & 0.278 & 1.349 & 0.223 & & & & & & & & \\
\hline $\begin{array}{l}\text { Heart rate } \\
\text { (beats per } \\
\text { minute) }\end{array}$ & 1.039 & 1.017 & 1.062 & 0.001 & 1.030 & 1.006 & 1.055 & 0.014 & 1.024 & 1.001 & 1.049 & 0.045 \\
\hline $\begin{array}{l}\text { Alanine } \\
\text { transaminase } \\
(\mathrm{IU} / \mathrm{L})\end{array}$ & 1.019 & 1.007 & 1.031 & 0.002 & 1.009 & 0.995 & 1.024 & 0.199 & 1.008 & 0.994 & 1.022 & 0.278 \\
\hline $\begin{array}{l}\text { Acute } \\
\text { ischemic } \\
\text { limb (yes or } \\
\text { no) }\end{array}$ & 3.367 & 1.401 & 8.088 & 0.007 & 1.740 & 0.589 & 5.139 & 0.316 & 1.024 & 0.327 & 3.203 & 0.968 \\
\hline $\begin{array}{l}\text { Rutherford } \\
\text { classification } \\
\text { (IV, V or VI) }\end{array}$ & 1.001 & 0.475 & 2.110 & 0.997 & 1.108 & 0.486 & 2.527 & 0.807 & 0.899 & 0.404 & 2.012 & 0.795 \\
\hline \multicolumn{13}{|c|}{ Major adverse cardiac events at one year } \\
\hline $\begin{array}{l}\text { NLR as a } \\
\text { continuous } \\
\text { variable }^{a}\end{array}$ & 1.014 & 0.990 & 1.038 & 0.267 & 1.007 & 0.974 & 1.041 & 0.681 & & & & \\
\hline $\begin{array}{l}\text { NLR } \geq 8 \text { vs. }< \\
8^{a}\end{array}$ & 2.503 & 1.290 & 4.858 & 0.007 & & & & & 1.864 & 0.858 & 4.049 & 0.116 \\
\hline Age (years) & 1.012 & 0.981 & 1.043 & 0.459 & 0.993 & 0.960 & 1.026 & 0.665 & 0.993 & 0.960 & 1.027 & 0.694 \\
\hline Male gender & 0.766 & 0.394 & 1.490 & 0.432 & 0.628 & 0.311 & 1.268 & 0.194 & 0.609 & 0.302 & 1.230 & 0.167 \\
\hline $\begin{array}{l}\text { Body mass } \\
\text { index } \\
\left(\mathrm{kg} / \mathrm{m}^{2}\right)\end{array}$ & 0.942 & 0.864 & 1.027 & 0.176 & 0.933 & 0.851 & 1.023 & 0.142 & 0.933 & 0.851 & 1.023 & 0.139 \\
\hline $\begin{array}{l}\text { Smoking (yes } \\
\text { or no) }\end{array}$ & 1.472 & 0.881 & 2.458 & 0.140 & & & & & & & & \\
\hline $\begin{array}{l}\text { Hypertension } \\
\text { (yes or no) }\end{array}$ & 0.741 & 0.377 & 1.457 & 0.385 & & & & & & & & \\
\hline $\begin{array}{l}\text { Heart rate } \\
\text { (beats per } \\
\text { minute) }\end{array}$ & 1.025 & 1.007 & 1.043 & 0.005 & 1.027 & 1.007 & 1.049 & 0.009 & 1.025 & 1.005 & 1.046 & 0.017 \\
\hline $\begin{array}{l}\text { Alanine } \\
\text { transaminase } \\
(\mathrm{IU} / \mathrm{L})\end{array}$ & 1.008 & 0.997 & 1.020 & 0.147 & & & & & & & & \\
\hline $\begin{array}{l}\text { Acute } \\
\text { ischemic } \\
\text { limb (yes or } \\
\text { no) }\end{array}$ & 2.381 & 1.115 & 5.085 & 0.025 & 2.324 & 0.976 & 5.531 & 0.057 & 1.799 & 0.709 & 4.566 & 0.217 \\
\hline $\begin{array}{l}\text { Rutherford } \\
\text { classification } \\
\text { (IV, V or VI) }\end{array}$ & 1.033 & 0.561 & 1.903 & 0.917 & 1.097 & 0.577 & 2.085 & 0.777 & 1.015 & 0.529 & 1.945 & 0.965 \\
\hline
\end{tabular}

a NLR as a continuous variable and NLR as a binary variable were not simultaneously adjusted in the multivariate logistic regression analyses. $\mathrm{cHR}=$ crude hazard ratio; aHR = adjusted hazard ratio; $\mathrm{Cl}$ : confidence interval. 


\begin{tabular}{|c|c|c|c|c|c|c|c|c|c|c|c|c|}
\hline & cHR & $95 \% \mathrm{Cl}$ & & $P$ & aHR & $95 \% \mathrm{Cl}$ & & $P$ & aHR & $95 \% \mathrm{Cl}$ & & $\mathbf{P}$ \\
\hline $\begin{array}{l}\text { NLR as a } \\
\text { continuous } \\
\text { variable }^{a}\end{array}$ & 1.012 & 0.987 & 1.038 & 0.346 & 0.998 & 0.965 & 1.031 & 0.897 & & & & \\
\hline $\begin{array}{l}\text { NLR } \geq 6 \text { vs. }< \\
6^{a}\end{array}$ & 3.286 & 1.601 & 6.746 & 0.001 & & & & & 2.804 & 1.292 & 6.088 & 0.009 \\
\hline Age (years) & 0.977 & 0.950 & 1.004 & 0.097 & 0.952 & 0.921 & 0.985 & 0.004 & 0.956 & 0.924 & 0.990 & 0.012 \\
\hline Male gender & 1.247 & 0.634 & 2.455 & 0.522 & 1.376 & 0.672 & 2.819 & 0.382 & 1.350 & 0.655 & 2.783 & 0.416 \\
\hline $\begin{array}{l}\text { Body mass } \\
\text { index } \\
\left(\mathrm{kg} / \mathrm{m}^{2}\right)\end{array}$ & 0.955 & 0.876 & 1.040 & 0.288 & 0.917 & 0.836 & 1.007 & 0.069 & 0.924 & 0.840 & 1.016 & 0.104 \\
\hline $\begin{array}{l}\text { Smoking (yes } \\
\text { or no) }\end{array}$ & 1.052 & 0.570 & 1.941 & 0.872 & & & & & & & & \\
\hline $\begin{array}{l}\text { Hypertension } \\
\text { (yes or no) }\end{array}$ & 0.806 & 0.404 & 1.610 & 0.541 & & & & & & & & \\
\hline $\begin{array}{l}\text { Heart rate } \\
\text { (beats per } \\
\text { minute) }\end{array}$ & 0.998 & 0.979 & 1.017 & 0.816 & & & & & & & & \\
\hline $\begin{array}{l}\text { Alanine } \\
\text { transaminase } \\
(\mathrm{IU} / \mathrm{L})\end{array}$ & 1.001 & 0.987 & 1.016 & 0.852 & & & & & & & & \\
\hline $\begin{array}{l}\text { Acute } \\
\text { ischemic } \\
\text { limb (yes or } \\
\text { no) }\end{array}$ & 0.830 & 0.292 & 2.355 & 0.726 & 0.725 & 0.210 & 2.498 & 0.610 & 0.506 & 0.143 & 1.786 & 0.290 \\
\hline $\begin{array}{l}\text { Rutherford } \\
\text { classification } \\
\text { (IV, V or VI) }\end{array}$ & 3.938 & 2.101 & 7.382 & $\begin{array}{l}< \\
0.001\end{array}$ & 5.346 & 2.531 & 11.291 & $<.001$ & 4.429 & 2.087 & 9.400 & $\begin{array}{l}<.001 \\
0.001\end{array}$ \\
\hline \multicolumn{13}{|c|}{ In-hospital mortality } \\
\hline $\begin{array}{l}\text { NLR as a } \\
\text { continuous } \\
\text { variable }^{a}\end{array}$ & 1.012 & 0.965 & 1.061 & 0.626 & & & & & & & & \\
\hline $\begin{array}{l}\text { NLR } \geq 5 \text { vs. }< \\
5^{a}\end{array}$ & 0.649 & 0.174 & 2.418 & 0.519 & & & & & & & & \\
\hline Age (years) & 0.992 & 0.947 & 1.040 & 0.752 & & & & & & & & \\
\hline Male gender & 0.421 & 0.147 & 1.207 & 0.108 & & & & & & & & \\
\hline $\begin{array}{l}\text { Body mass } \\
\text { index } \\
\left(\mathrm{kg} / \mathrm{m}^{2}\right)\end{array}$ & 1.050 & 0.898 & 1.227 & 0.542 & & & & & & & & \\
\hline $\begin{array}{l}\text { Smoking (yes } \\
\text { or no) }\end{array}$ & 1.308 & 0.440 & 3.892 & 0.629 & & & & & & & & \\
\hline $\begin{array}{l}\text { Hypertension } \\
\text { (yes or no) }\end{array}$ & 1.074 & 0.404 & 2.861 & 0.886 & & & & & & & & \\
\hline $\begin{array}{l}\text { Heart rate } \\
\text { (beats per } \\
\text { minute) }\end{array}$ & 0.999 & 0.981 & 1.018 & 0.954 & & & & & & & & \\
\hline
\end{tabular}




\begin{tabular}{|c|c|c|c|c|c|c|c|c|c|c|}
\hline & $\mathrm{cHR}$ & $95 \% \mathrm{Cl}$ & & $P$ & aHR & $95 \% \mathrm{Cl}$ & $P$ & aHR & $95 \% \mathrm{Cl}$ & $\mathbf{P}$ \\
\hline $\begin{array}{l}\text { Alanine } \\
\text { transaminase } \\
\text { (IU/L) }\end{array}$ & 0.997 & 0.985 & 1.010 & 0.660 & & & & & & \\
\hline $\begin{array}{l}\text { Acute } \\
\text { ischemic } \\
\text { limb (yes or } \\
\text { no) }\end{array}$ & 0.664 & 0.253 & 1.746 & 0.407 & & & & & & \\
\hline $\begin{array}{l}\text { Rutherford } \\
\text { stages (IV, V } \\
\text { or VI) }\end{array}$ & 1.374 & 0.670 & 2.816 & 0.386 & & & & & & \\
\hline $\begin{array}{l}\text { White blood } \\
\text { count }\end{array}$ & 1.000 & 1.000 & 1.000 & 0.134 & & & & & & \\
\hline Neutrophils & 0.986 & 0.938 & 1.036 & 0.574 & & & & & & \\
\hline Lymphocytes & 1.042 & 0.958 & 1.134 & 0.339 & & & & & & \\
\hline
\end{tabular}

After we adjusted for confounders in the multivariate logistic regression analyses, each incremental increase in NLR was significantly associated with increased all-cause mortality (adjusted HR: $1.028,95 \% \mathrm{Cl}: 1.008-1.049, \mathrm{P}=0.007$ ) and cardiacrelated mortality (adjusted HR: 1.027, 95\% Cl: 0.998-1.057, P = 0.073), but there was no significant association between NLR and either MACE or MALE. NLR $\geq 8$ and NLR $<8$ were significantly associated with all-cause mortality (adjusted HR: $3.599,95 \% \mathrm{Cl}$ : 1.818-7.123, $\mathrm{P}<0.001$ ) and cardiac-related mortality (adjusted HR: $5.286,95 \% \mathrm{Cl}: 2.075-13.47, \mathrm{P}<0.001)$ but not MACE. NLR $\geq$ 6 and NLR $<6$ were significantly associated with MALE (adjusted HR: $2.804,95 \%$ Cl: $1.292-6.088, P=0.009$ ) (Table 2). KaplanMeier curves demonstrating the incidence of the study outcomes are shown in Fig. 2.

\section{Discussion}

In the present study, we show that elevated NLR was associated with one-year all-cause and cardiac-related mortality in patients with CLI but was not associated with one-year MACE or MALE. The associations between the NLR and our study outcomes can be clinically explained by the functions of neutrophils and lymphocytes in the human immune system. The percentage of white blood cells accounted for by neutrophils increases as the immune response activates against bacterial infection in CLI patients with sepsis; a higher neutrophil ratio indicates a stronger inflammatory response and is associated with a poor prognosis in patients with LEAD ${ }^{14}$. Lymphocytes play a role in adaptive immunity, and a lower lymphocyte ratio was found to indicate a lower survival probability in previous studies of patients with sepsis ${ }^{15}$. In our study, patients with a lower lymphocytes ratio were relatively immunocompromised and predisposed to all-cause mortality resulting from CLI-induced sepsis. In addition, experimental evidence has shown that lymphocytes activate and modify ischemia-reperfusion injury and wound healing ${ }^{16}$. As mentioned above, the NLR is an inflammatory biomarker and a biomarker of poor wound healing in patients with CLI that is associated with an increased risk of all-cause mortality. Statistically, the neutrophil ratio was positively associated and the lymphocyte ratio was inversely associated with all-cause mortality. As it considers both the neutrophil and the lymphocyte ratios with regard for all-cause mortality, the NLR is a more powerful predictor of all-cause mortality than using wither the neutrophil or lymphocyte ratio alone.

A strength of our study is that we report comprehensive outcomes, including MACE. All-cause mortality has been reported in many studies ${ }^{12,17-20}$, cardiac morality in only a few studies ${ }^{12,18}$, and amputation in only a few studies ${ }^{12,17,19,20}$; however, no study has previously reported MACE and MALE in patients with CLI or stable LEAD with regard for the NLR. The best cut-off for NLR, as determined by receiver operating characteristic curves, was eight in the present study, but this cut-off for NLR is not consistent with previous studies, in which it has also not been universal and ranges from three to five $\mathrm{e}^{12,13,17-20}$. Spark et al. ${ }^{12}$ 
previously reported that NLR $\geq 5.25$ vs. NLR $<5.25$ was associated with all-cause mortality, and an NLR cut-off of 5.25 was further validated in the study by Chan et al. ${ }^{18}$ Notably, the study by Spark et al. ${ }^{12}$ enrolled patients with Rutherford stages IV and $\mathrm{V}$ but not Rutherford stage $\mathrm{VI}$, and Chan et al. ${ }^{18}$ enrolled only one patient (less than 1\%) with Rutherford stage VI. In the study by Erturk et al. ${ }^{13}$, the NLR cut-off was even lower, at three, because more than sixty percent of the patients were at Rutherford stages III and IV. The major differences between our and other studies are related to the study populations; compared to previous investigators who enrolled patients with peripheral artery diseases and weaker inflammatory responses, we enrolled CLI patients with stronger inflammatory responses ${ }^{13,19}$. In other words, the neutrophil ratio in our patients indicates a stronger inflammatory response, whereas patients in the other study had weaker inflammation ${ }^{12}$. In studies that enrolled patients with either CLI or stable LEAD ${ }^{19}$, the cut-off for NLR may be reduced by the patients with stable LEAD, and the resulting lower NLR threshold may be unable to adequately stratify CLI patients with higher cardiovascular risks. We conducted the present study by enrolling only CLI patients while excluding patients with stable LEAD to make our study population homogeneous, and we therefore suggest that an NLR cut-off of eight could be used in CLI patients to evaluate the risk of all-cause mortality in future studies.

The NLR value increased with higher Rutherford stages in the present study, consistent with a previous study by Bath et al. ${ }^{19}$ Another study also showed that disease severity and the values of high-sensitivity C-reactive protein significantly increased across tertiles of NLR in patients with lower limb arteriosclerosis obliterans ${ }^{20}$. NLR, as a biomarker of the inflammatory response and disease severity, has been proposed to contribute to mortality in CLI patients, but NLR as a continuous variable was not associated with MALE in the present study. The NLR was also associated with the complexity of CLI-related arteries, and atherothrombosis has also been shown to be an additional risk factor for MALE in patients with CLI ${ }^{21,22}$. Because CLI patients had increased platelet activation at baseline than was found in healthy subjects ${ }^{23}$, the platelet to lymphocyte ratio may be a better predictor of incident MALEs in CLI patients ${ }^{17}$.

A weakness of our study is that we found that the prescription of medication for CLI patients was relatively low at baseline, including the use of statin and angiotensin-converting enzyme inhibitors or angiotensin receptor blockers. Additionally, the allcause mortality rate was as high at approximately $25.4 \%$, and the rate of MALE was $17.3 \%$. A meta-analysis that included thirteen studies showed that the rates of all-cause mortality and MALE were both $22 \%$ in the natural history of untreated CLI patients ${ }^{24}$. Another retrospective cohort study showed that four-year mortality was significantly higher among the subgroups at $37.7 \%$, $52.2 \%$, and $63.5 \%$ in Rutherford stages IV, V, and VI, respectively; while the four-year rates of amputation were $12.1 \%, 35.3 \%$, and $67.3 \%$ for Rutherford classification IV, $\mathrm{V}$, and $\mathrm{VI}$, respectively ${ }^{25}$. The REACH registry showed that statin use was significantly associated with a decreased risk of mortality in patients with artherothrombosis ${ }^{22}$. Although the present study was an all-comer study, the guideline-direct medical therapy to patients at the stage of symptomatic or asymptomatic LEAD could be enhanced to improve clinical outcomes before these patients present with CLI. Given that statins have anti-inflammatory properties and pleiotropic effects on reducing mortality and MALE, future studies should investigate the effect of statin intensity on changes in NLR. Second, the prescription rate of anti-platelet agents was sixty percent at baseline in the CLI patients, while the rate at discharge was $97 \%$. The contemporary guidelines suggest that an anti-platelet, such as aspirin or clopidogrel, is strongly recommended in patients with LEAD ${ }^{26}$. Although we prescribed anti-platelet agents to CLI patients according to the affordable rule of the National Health Insurance program, mortality and MALE remained high. The high incidence of mortality and MALE in the CLI patients in the present and previous studies indicates that the use of only anti-platelet agents might not be good enough to prevent future cardiovascular events. A previous double randomized controlled trial enrolled patients with atherosclerotic cardiovascular diseases and showed that compared to aspirin alone, low-dose rivaroxaban plus aspirin reduced MALE with the trade-off of bleeding complications ${ }^{27}$. The VOYAGER study randomized patients with LEAD undergoing revascularization to a low-dose rivaroxaban plus aspirin group or an aspirin alone group and found that randomization to low-dose rivaroxaban plus aspirin was associated with the significantly lower incidence of MACE and MALE than randomization to aspirin alone ${ }^{27}$; the trade-off of an increased risk of major bleeding was also reported in the VOYAGER study. Regarding the net clinical benefit of reduced MALE and increased bleeding complications, we propose that NLR $\geq 8$ may be useful for stratifying CLI patients with a high risk of mortality who may benefit from additional low-dose rivaroxaban in addition to aspirin.

Another limitation is that we investigated the association between NLR and several outcomes, but the best cut-off of NLR was not consistent across all study outcomes in our own study. NLR $\geq 8$ vs. $<8$ was associated with an increased risk of mortality but 
not MALE, whereas NLR $\geq 6$ vs. NLR $<6$ was associated with the incidence of MALE. Given that it would be difficult to apply multiple cut-off values in a clinical setting and difficult to validate them externally in other studies, we suggest that a cut-off of NLR $\geq 8$ vs. $<8$ may be adequate for identifying CLI patients at a risk of high mortality. Other predictors, such as the plateletlymphocyte ratio, should also be investigated regarding the incidence of MALE in CLI patients. In addition, a systematic review and meta-analysis could be performed to determine the best cut-off value for NLR among patients with LEAD with various risks.

We previously reported that elevated serum uric acid was associated with the prevalence of metabolic syndrome, left ventricular hypertrophy, left ventricular diastolic dysfunction in various study populations such as apparently healthy individuals, patients with cardiometabolic abnormalities, and patients with ST-segment elevation myocardial infarction ${ }^{28-31}$. However, we did not find a significant association between hyperuricemia and MACE and MALE in the present study. The possible explanation may be that serum uric acid serves as weaker inflammation, and it, therefore, did not play a role in CLI patients with stronger inflammatory responses.

In conclusion, we show that CLI patients with a higher NLR have significantly higher incidences of all-cause and cardiac-related mortality and MALE at one year. Each increment in NLR was associated with an increased risk of all-cause and cardiac-related mortality but not MALE. NLR $\geq 8$ vs. NLR $<8$ can be used to predict mortality in CLI patients.

\section{Methods}

We retrospectively and continuously enrolled patients with CLI undergoing percutaneous transluminal angioplasty at our hospital between 2013/1/1 and 2018/12/31. The study patients were all-comers, with the only specific exclusion criterion CLI patients with a nonsalvageable limb who refused amputation surgery. We divided the study patients into higher and lower NLR groups and collected the patients' baseline characteristics, laboratory data, procedural details, and outcomes from medical records. All patients were followed up until 2019/12/31. Given that the present study was a retrospective cohort study with a low risk, no informed consent was needed from the study patients. The study was approved by the Mackay Memorial Hospital with Institutional Review Board number (20MMHIS034e). The informed consent was waived by the Mackay memorial hospital institutional review board because the present study is a low-risk retrospective cohort study. The present study was conducted in accordance with the Declaration of Helsinki.

Patients who present to our emergency department with CLI routinely receive dual anti-platelet therapy with aspirin plus clopidogrel, and heparinization is loaded according to the guidelines unless contraindicated. We do not routinely prescribe cilostazol to patients with CLI. During this study, patients who presented with acute limb ischemia were treated by emergent percutaneous transluminal angioplasty, and patients with chronic limb ischemia were treated by urgent percutaneous transluminal angioplasty. In our cardiac catheterization laboratory, the physicians decided whether to use an antegrade or retrograde approach depending on a patient's lesion type. Heparin was administered to maintain an active clotting time between 250 and 300 seconds. Because of our national health insurance rules, we generally treat iliac and femoropopliteal lesions with balloon angioplasty, a drug-coated balloon or a stent and below-knee lesions with only balloon angioplasty; use of a drug-coated balloon or stent was left to the physicians' decision and was mainly influenced by the patients' economic status. At discharge, dual anti-platelet agents were continued for at least one month unless clinically significant bleeding complications developed.

CLI was defined according to the Rutherford classification, including rest pain (stage IV), tissue loss (stage V), and gangrene $(\text { stage } \mathrm{VI})^{32}$. The primary study outcomes were all-cause mortality, cardiac-related mortality, MACE, and MALE at the one-year follow-up. MACE was defined as the composite of nonfatal myocardial infarction, nonfatal stroke, and cardiac-related death; MALE was defined as an amputation due to a vascular event above the forefoot, acute limb ischemia and clinically driven target vessel revascularization. Secondary outcomes were in-hospital all-cause mortality.

Continuous variables are presented as numbers and standard deviations, and binary variables are presented as numbers and percentages; independent t-tests and chi-squared tests were used to evaluate differences in continuous variables and binary variables, respectively. We used receiver operating characteristic curves to identify NLR cut-off values for each study outcome. We used univariate logistic regression analyses to investigate the associations between NLR and study outcomes and between variables and study outcomes. Variables that were significantly associated with the study outcomes were considered

Page 12/16 
confounders, and they were adjusted in multivariate logistic regression analyses. The presence of acute limb ischemia and Rutherford classification criteria were major risk factors associated with outcomes in patients with CLI and were adjusted in the multivariate logistic regression analyses to determine whether they were significantly associated with the study outcomes identified in the univariate logistic regression analyses. All $P$ values are two-tailed, and $P$ values of 0.05 or lower were considered significant. We performed all statistical analyses with Statistical Package for the Social Sciences (SPSS software, version 20.0).

\section{Declarations}

\section{Data availability:}

The correspondence can provided the anonymous study data if a request is judged as reasonable.

\section{Author contributions:}

Min-I Su designed the study and collected the data. Cheng-Wei Liu performed the statistical analyses, wrote the manuscript, and is responsible for correspondence.

\section{Competing interests:}

The authors declare no competing interests.

\section{References}

1. Faria, S. S. et al. The neutrophil-to-lymphocyte ratio: a narrative review. Ecancermedicalscience 10, 702 (2016).

2. Li, X. et al. The value of neutrophil-to-lymphocyte ratio for response and prognostic effect of neoadjuvant chemotherapy in solid tumors: a systematic review and meta-analysis. J. Cancer 9, 861-871 (2018).

3. Silvestre-Roig, C., Braster, Q., Ortega-Gomez, A. \& Soehnlein, O. Neutrophils as regulators of cardiovascular inflammation. Nat. Rev. Cardiol. 17, 327-340 (2020).

4. Albrengues, J. et al. Neutrophil extracellular traps produced during inflammation awaken dormant cancer cells in mice. Science 361, eaao4227 (2018).

5. Izaks, G. J., Remarque, E. J., Becker, S. V. \& Westendorp, R. G. Lymphocyte count and mortality risk in older persons. The Leiden 85-plus study. J. Am. Geriatr. Soc. 51, 1461-1465 (2003).

6. Angkananard, T., Anothaisintawee, T., McEvoy, M., Attia, J. \& Thakkinstian, A. Neutrophil lymphocyte ratio and cardiovascular disease risk: a systematic review and meta-analysis. BioMed Res. Int. 2018, 2703518 (2018).

7. Bhat, T. M., Afari, M. E. \& Garcia, L. A. Neutrophil lymphocyte ratio in peripheral vascular disease: a review. Expert Rev. Cardiovasc. Ther. 14, 871-875 (2016).

8. Song, S. Y. et al. Clinical significance of baseline neutrophil-to-lymphocyte ratio in patients with ischemic stroke or hemorrhagic stroke: an updated meta-analysis. Front. Neurol. 10, 1032 (2019).

9. Zhang, S. et al. Predictive value of neutrophil to lymphocyte ratio in patients with acute ST segment elevation myocardial infarction after percutaneous coronary intervention: a meta-analysis. BMC Cardiovasc. Disord. 18, 75 (2018).

10. Teperman, J. et al. Relationship between neutrophil-lymphocyte ratio and severity of lower extremity peripheral artery disease. Int. J. Cardiol. 228, 201-204 (2017).

11. Aykan, A. C. et al. Neutrophil-to-lymphocyte ratio may be a marker of peripheral artery disease complexity. Anatol. J. Cardiol. 16, 497-503 (2016).

12. Spark, J. I., Sarveswaran, J., Blest, N., Charalabidis, P. \& Asthana, S. An elevated neutrophil-lymphocyte ratio independently predicts mortality in chronic critical limb ischemia. J. Vasc. Surg. 52, 632-636 (2010).

13. Erturk, M. et al. Predictive value of elevated neutrophil to lymphocyte ratio for long-term cardiovascular mortality in peripheral arterial occlusive disease. J. Cardiol. 64, 371-376 (2014). 
14. Signorelli, S. S., Fiore, V. \& Malaponte, G. Inflammation and peripheral arterial disease: the value of circulating biomarkers (Review). Int. J. Mol. Med. 33, 777-783 (2014).

15. De Pablo, R., Monserrat, J., Prieto, A. \& Alvarez-Mon, M. Role of circulating lymphocytes in patients with sepsis. BioMed Res. Int. 2014, 671087 (2014).

16. Hofmann, U. \& Frantz, S. Role of lymphocytes in myocardial injury, healing, and remodeling after myocardial infarction. Circ. Res. 116, 354-367 (2015).

17. Tasoglu, I. et al. Neutrophil-lymphocyte ratio and the platelet-lymphocyte ratio predict the limb survival in critical limb ischemia. Clin. Appl. Thromb. Hemost. 20, 645-650 (2014).

18. Chan, C., Puckridge, P., Ullah, S., Delaney, C. \& Spark, J. I. Neutrophil-lymphocyte ratio as a prognostic marker of outcome in infrapopliteal percutaneous interventions for critical limb ischemia. J. Vasc. Surg. 60, 661-668 (2014).

19. Bath, J., Smith, J. B., Kruse, R. L. \& Vogel, T. R. Neutrophil-lymphocyte ratio predicts disease severity and outcome after lower extremity procedures. J. Vasc. Surg. 72, 622-631 (2020).

20. Ye, M. et al. Neutrophil-lymphocyte ratio and platelet-lymphocyte ratio predict severity and prognosis of lower limb arteriosclerosis obliterans. Ann. Vasc. Surg. 64, 221-227 (2020).

21. Kinlay, S. Management of critical limb ischemia. Circ. Cardiovasc. Interv. 9, e001946 (2016).

22. Bhatt, D. L. et al. Comparative determinants of 4-year cardiovascular event rates in stable outpatients at risk of or with atherothrombosis. JAMA 304, 1350-1357 (2010).

23. Wisman, P. P. et al. Baseline platelet activation and reactivity in patients with critical limb ischemia. PLoS One 10, e0131356 (2015).

24. Dabrh, A. M. A. et al. The natural history of untreated severe or critical limb ischemia. J. Vasc. Surg. 62, 1642-1651.e3 (2015).

25. Reinecke, H. et al. Peripheral arterial disease and critical limb ischaemia: still poor outcomes and lack of guideline adherence. Eur. Heart J. 36, 932-938 (2015).

26. Kithcart, A. P. \& Beckman, J. A. ACC/AHA versus ESC guidelines for diagnosis and management of peripheral artery disease: JACC guideline comparison. J. Am. Coll. Cardiol. 72, 2789-2801 (2018).

27. Anand, S. S. et al. Rivaroxaban with or without aspirin in patients with stable peripheral or carotid artery disease: an international, randomised, double-blind, placebo-controlled trial. Lancet 391, 219-229 (2018).

28. Liu, C. W. et al. Hyperuricemia is associated with a higher prevalence of metabolic syndrome in military individuals. Mil. Med. 183, e391-e395 (2018).

29. Liu, C. W. et al. The dose-response effects of uric acid on the prevalence of metabolic syndrome and electrocardiographic left ventricular hypertrophy in healthy individuals. Nutr. Metab. Cardiovasc. Dis. 29, 30-38 (2019).

30. Liu, C. W. \& Lin, T. C. Serum uric acid was an independent predictor of mortality in ST-segment elevation myocardial infarction patients with Killip I other than Killip II-IV. J. Cardiovasc. Thorac. Res. 9, 62-63 (2017).

31. Liu, C. W. et al. Association between low-grade inflammation and left ventricular diastolic dysfunction in patients with metabolic syndrome and hyperuricemia. Acta Cardiol. Sin. 36, 483-492 (2020).

32. Shishehbor, M. H. et al. Critical limb ischemia: an expert statement. J. Am. Coll. Cardiol. 68, 2002-2015 (2016).

\section{Supplemental Materials}

Supplemental tables showed baseline and procedural characteristics and laboratory data in patients with critical limb ischemia (NLR $\geq 5$ vs. NLR $<5$ in table 1 and NLR $\geq 6$ vs. NLR $<6$ in Supplementary Table S2).

\section{Figures}



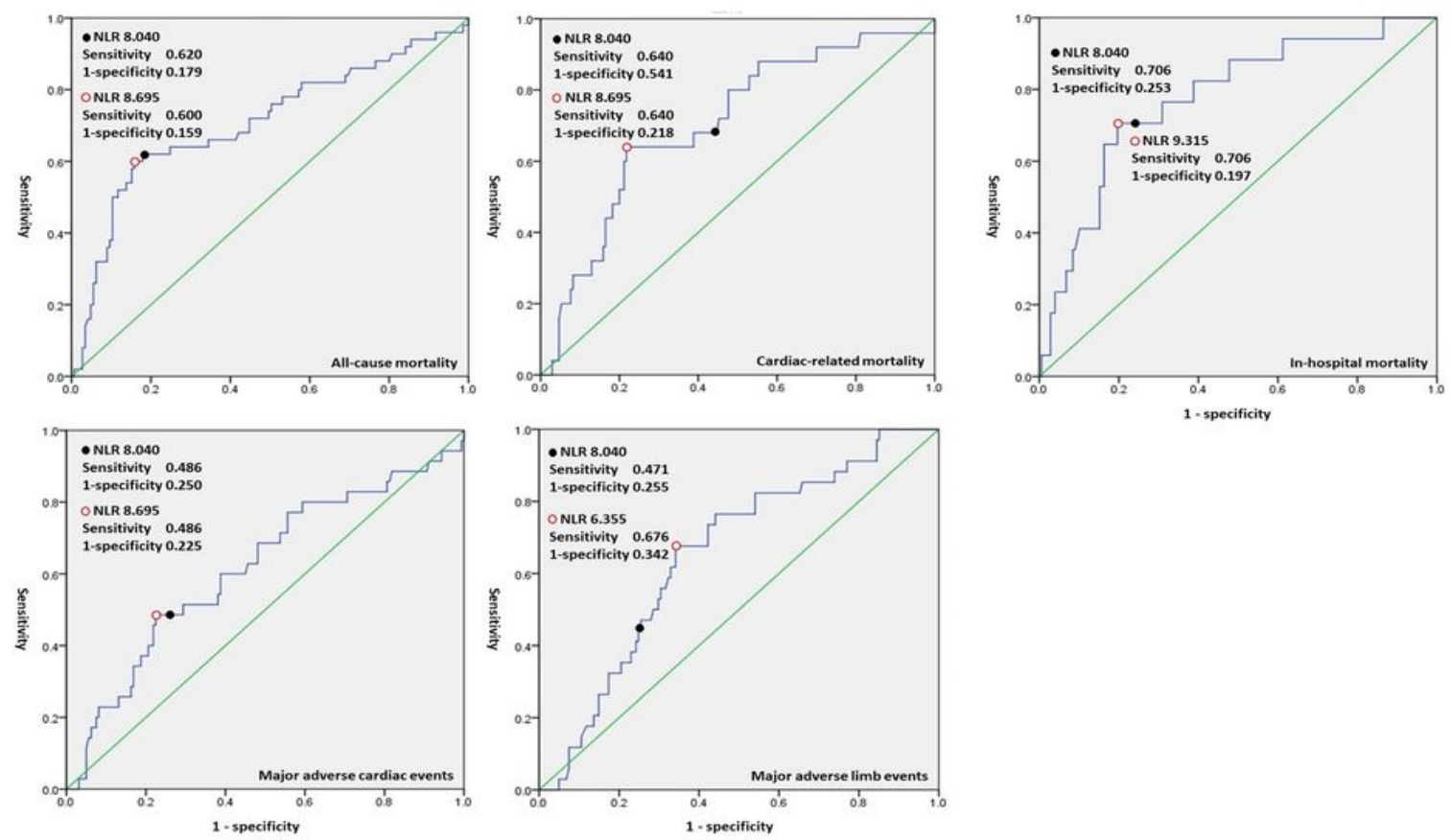

\section{Figure 1}

Receiver operating characteristic curves showing the NLR cut-off for each study outcome. 

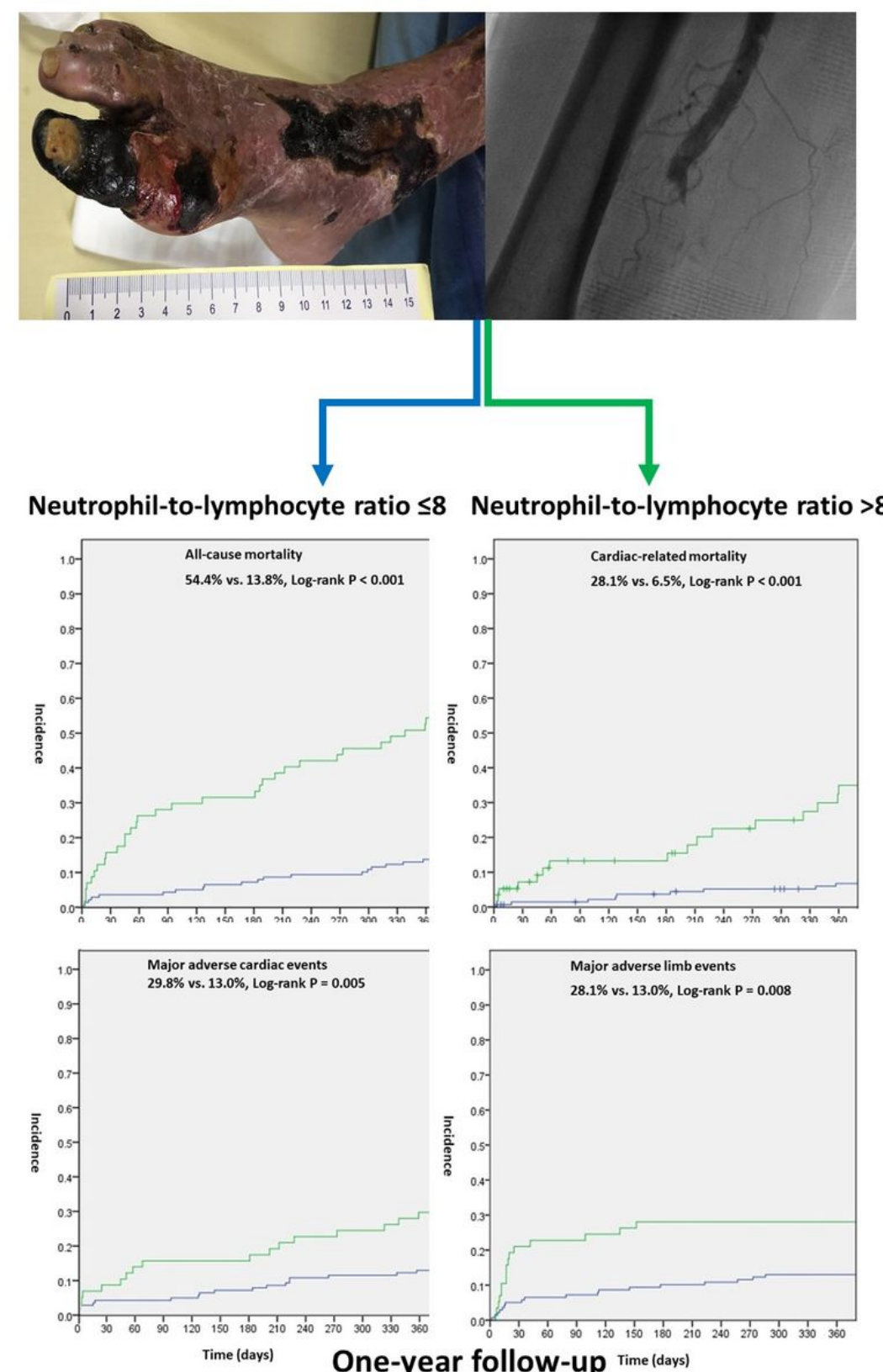

One-year follow-up time (days)

\section{Figure 2}

Kaplan-Meier curves showing that the risks of one-year all-cause (a) and cardiac-related (b) mortality, MACE (c), MALE (d), and inhospital mortality were significantly higher in CLI patients with NLR $\geq 8$ than in those with NLR $<8$.

\section{Supplementary Files}

This is a list of supplementary files associated with this preprint. Click to download.

- Tables1.docx

- Tables2.docx 